Article

\title{
Education and "Categorical Inequalities": Manifestation of Segregation in Six Country Contexts in Europe
}

\author{
Başak Akkan * and Ayşe Buğra \\ Social Policy Forum, Boğaziçi University, Turkey; E-Mails: basak.akkan@boun.edu.tr (B.A.), bugray@boun.edu.tr (A.B) \\ * Corresponding author
}

Submitted: 22 March 2021 | Accepted: 25 May 2021 | Published: 16 September 2021

\begin{abstract}
This article deals with the educational arrangements and the multiple inequalities that they reproduce from a comparative perspective. Drawing on a qualitative study conducted in six countries (Austria, Hungary, Netherlands, Portugal, Turkey, and the UK) as part of a multinational research project concerning justice in Europe, the article explores the mechanisms through which education sustains and reproduces "categorical inequalities." Although equal access to education is granted by constitutional laws as well as by incorporation of international treaties in the national legal frameworks, it is commonly the educational arrangements that identify the features of access to good quality education in a given context. Dealing with different country cases that have their path dependencies in the arrangements of education, the article provides insights on understanding how different features of segregation in education operate as mechanisms of exclusion for students from a disadvantaged background. Hence, the disadvantages manifest themselves concerning socio-economic status, ethnicity, race, and minority background. By focusing on the country-based debates around school segregation, which goes together with the segregated character of urban settings and school choice patterns, the article shows how the institutional context with or without residency-based registration rules and different types of schools with different resources perpetuate multiple inequalities. In a context where educational arrangements operate as a mechanism of sustaining categorical inequalities, identity-based differences, combined with economic disadvantages lead to a situation where students from vulnerable and minority groups face multiple forms of exclusion.
\end{abstract}

\section{Keywords}

educational arrangements; multiple inequalities; residential segregation; school choice; school segregation

Issue

This article is part of the issue "Education, Politics, Inequalities: Current Dynamics and Perspectives" edited by Kenneth Horvath (University of Lucerne, Switzerland) and Regula Julia Leemann (University of Teacher Education FHNW, Switzerland / University of Basel, Switzerland).

(C) 2021 by the authors; licensee Cogitatio (Lisbon, Portugal). This article is licensed under a Creative Commons Attribution 4.0 International License (CC BY).

\section{Introduction}

This article deals with the institutional arrangements of education and the multiple inequalities that they reproduce from a comparative perspective. Drawing on six country cases including Austria, Hungary, Netherlands, Portugal, Turkey, and the UK, the article explores the mechanisms through which education sustains and perpetuates the multiple inequalities. Although education is granted as a fundamental right by law in the countries under study, several mechanisms come into play and hinder equal access to quality education.

The institutional arrangements of education (referred to as educational arrangements in the article) often determine the majority and minority relations and draw the boundaries of inclusion and exclusion in a given context. Inclusive education that has egalitarian aspirations could not be difference-blind in our pluralistic societies, yet the mechanism of accommodating difference in the education system could reinforce 
further exclusion and inequality. Hence, inequalities do not just take the form of socio-economic differences, but other identity and gender-based differences could operate as "categorical inequalities" (Tilly, 1999). Feminist research also demonstrated that different social categories intersect and lead to complex forms of inequalities (Collins, 1998). In this respect, the "categorisation of differences" (Knijn \& Akkan, 2020) and reproduction of "categorical inequalities" through educational arrangements (Domina et al., 2017) operate as mechanisms that sustain persistent inequalities in society. Respectively, education emerges as an "inequality-creating phenomenon" (Winker \& Degele, 2011) and becomes the main determinant of capability deprivation of children from minority and vulnerable groups.

Exclusionary barriers to education have overlapping socioeconomic and spatial determinants. The literature draws attention to the persistent forms of segregation in education that are reinforced by the segregated nature of the underprivileged neighbourhoods with disadvantaged schools. The factors that generate such discrepancies in the quality of education also lead to inequalities in the representation of minority groups in matters of education. The kind of voice and impact that parents have to influence the access processes might vary in a way to reflect socio-economic divides and spatial segregation. Drawing on the literature that addresses the educational inequalities, several questions are raised in the article: How do the educational arrangements in different country contexts pave the way for the segregated schools? How does this operate for vulnerable groups? How is it intertwined with the segregated character of urban settings in different country cases? How does school choice define the exclusionary process?

Although the study does not empirically look into the capability deprivation of children as an outcome of the exclusionary processes, the capability approach of Amartya Sen provides a normative framework as the exclusionary process of education is a matter of deprivation for children with a disadvantaged background. Capability deprivation as a result of the exclusionary mechanisms of education reinforces the persistent inequalities transferred over generations. In this framework, first, the article provides a descriptive analysis of the various institutional frameworks of the educational arrangements in the countries under study; second, it presents how educational arrangements operate as different mechanisms of exclusion, yet yield similar results concerning the role of education in the maintenance of "categorical inequalities."

\section{Theoretical Framework}

There is consensus in the literature that inequalities in access to education are predominantly determined by poverty and the disadvantaged background of children (Keddie, 2012; Unterhalter, 2003). Education, with its egalitarian objectives, has a vital role in eradicating persistent inequalities in society, yet literature demonstrates that education arrangements fortify and reproduce the multiple inequalities of class, gender, race, and others (Domina et al., 2017; Power, 2012; Tikly \& Barrett, 2011; Unterhalter, 2003). One framework suggested by Domina et al. (2017) that looks into the inequalityreproducing aspects of education by applying theories of categorical inequality provides significant insights to our analysis. The theory of categorical inequality suggests a framework for understanding how educational arrangements interact with broader social categories including gender, class, and race (Domina et al., 2017). In several circumstances, these broader categories intersect and lead to more complex inequalities as intersectionality literature also draws our attention (Collins, 1998; Unterhalter, 2003). The categorical inequality approach points to the organisational processes of education through which individuals are "sorted" (Domina et al., 2017 , p. 2); in other terms, categorised according to their difference (Knijn \& Akkan, 2020). The social categories establish the boundaries of inclusion and exclusion and define the distribution of resources as the categorical inequality theory suggests (Tilly, 1999). Hence, the schools create these categories by sorting students through the interplay of different mechanisms (Domina et al., 2017). The minority and vulnerable groups' access to education is a manifestation of how the boundaries of inclusion and exclusion are drawn by such educational arrangements.

School segregation is a major factor in reproducing educational inequalities, which have been studied extensively, and its effects on most disadvantaged students have been empirically presented (Benito et al., 2014; Bonal \& Bellei, 2018; Dupriez et al., 2008). School segregation perpetuates the stratification mechanism in society, which manifests not just the socio-economic differences, but also other vulnerabilities and minority positions in society. School segregation could further emerge as a form of racial discrimination like the segregation of Roma in the context of Central Europe (Arabadjieva, 2016). Several factors identify school segregation. These include language barriers of groups from minority and vulnerable backgrounds, residential segregation, parental choice (opting for high performing schools, choosing not to enrol their children in minority populated schools), and school separation for the sake of meeting the special needs of children (Council of Europe, 2017). There is strong evidence that the segregated nature of the school relates to students' disadvantaged backgrounds, which are also being reflected in PISA results (Alegre \& Ferrer, 2010). OECD PISA survey results reveal how the disadvantaged position of the family overlaps with the disadvantaged position of the school. Forty eight percent of the disadvantaged students attend disadvantaged schools, as demonstrated by the PISA cycles since 2006 (OECD, 2018). The OECD (2018) points to the "double disadvantage" that the children coming from disadvantaged backgrounds experience, as they attend 
the disadvantaged schools positioned in poor areas and neighbourhoods. Such interdependence defines educational performances. Students who come from more advantaged backgrounds, and whose classmates are also more advantaged, achieve better scores in the PISA assessment (OECD, 2018). For instance, the studies reveal that Roma-only schools provide less demanding and substandard education (Council of Europe, 2017). Strikingly, the countries with schools having high social and cultural heterogeneity in class (higher index of social inclusion) perform best in mathematics tests in PISA (OECD, 2013).

Residential segregation is an important aspect of school segregation which is always intertwined with other social categories like class, race, and ethnicity (Andersson et al., 2010; Arabadjieva, 2016; Bonal \& Bellei, 2018; Cashman, 2017; Domina et al., 2017). The low quality of schools in the so-called "pockets of poverty" is a major concern for school achievement as it reproduces categorical inequalities that pertain not just to class but also race and ethnicity (Alexiadou, 2019; Cashman, 2017; Shores et al., 2020). Residential segregation intermingles with other factors like school choice, which creates "circuits of schooling" (Bonal \& Bellei, 2018, p. 8; Butler \& Hamnett, 2007). In the last decades, respect for freedom of school choice has become a central norm in all contexts (Council of Europe, 2017; OECD, 2018). Yet, school choice could have adverse effects on students from disadvantaged backgrounds (Lynch \& Baker, 2005, p. 136). Parental preferences are mostly associated with the socio-economic but also migration background of families, and in many contexts the practices of school choice emerge as a "white flag" for middleclass families (Bonal \& Bellei, 2018; Bunar \& Ambrose, 2016). In the United States, race has always been a significant factor concerning school choice (Levin, 1998). Schools, depending on their residency, are segregated by race as white families make use of "magnet school choice programs" (Saporito, 2003). The school differentiation systems also define the school choice of parents, which identifies the ethnic composition of the school (Denessen et al., 2005). School segregation is a complex phenomenon where several factors interplay. Consequently, education becomes a contested terrain with its mechanisms of categorisation and segregation for disadvantaged groups, like Roma, who no longer believe that education overcomes their marginalisation in society (Sime et al., 2018). The literature reveals that in the last decades, marketisation has also reinforced the inequalities in accessing quality education as the widening gap between schools with and without resources affects the inequalities in the education outcomes among students from diverse socio-economic backgrounds (OECD, 2013, 2018; Power \& Frandji, 2010).

In a larger framework, understanding mechanisms of education that sustain the persistent inequalities with their multiple and complex forms pertains to the normative ideal of education for a just society. Sen iden- tifies education as "a relatively small number of centrally important beings and doings that are crucial to well-being" (Sen, 1992, p. 44, as cited in Walker, 2006, p. 163). The normative ideal of education is a precondition to the development of capabilities. According to Sen, the concept of capability entails the substantive freedom to achieve actual functionings (Sen, 1999, p. 75). While education is an "unqualified good for human development freedom" (Walker, 2006, p. 168), educational arrangements also reproduce inequalities and become an arena of "unfreedom" and capability deprivation (Tikly \& Barrett, 2011; Unterhalter, 2003; Walker, 2006). According to Sen, capability deprivation has a relational aspect and, in this respect, the social exclusion paradigm makes a useful contribution (Sen, 2000). There are diverse ways that social exclusion could cause deprivation. Hence, Sen (2000) points to the fact that social exclusion concerning the education arrangements pertains to a particular experience of poverty and deprivation for children with a disadvantaged background. Introducing here the relational understanding of justice and conception of capability help one to understand that access to good quality education that defines the persistent inequalities is a result of exclusionary processes that the education system creates. Despite its importance as a capability-building entity, education in our era as an inequality-creating institution defines the boundaries of inclusion and exclusion in every society.

Furthermore, education policies tackling inequalities prioritise the financial allocation of resources, government spending on education and access to free compulsory education for all (Power, 2012). As the country cases in our study also demonstrate, access to free compulsory education has become a priority in all contexts in tackling socio-economic inequalities. Yet, the disadvantaged background of a child does not just drive from the socio-economic status, as the literature demonstrates (Domina et al., 2017; Unterhalter, 2012). An inclusive education policy aims at redistributive politics without losing sight of the categorisation of differences as boundaries of exclusion and inclusion in a given context. The low socio-economic class of minority groups, immigration, racial segregation, language, and distribution of resources across the schools should be considered for the egalitarian objectives of education institutions (Allen \& Reich, 2013; Steiner-Khamsi, 2003). It is in this framework that we address education as a matter of justice and inequality with a particular focus on educational arrangements as mechanisms of inequality in six country contexts.

\section{Methodology}

The article is based on a qualitative study with elements of discourse analysis. Although the methodological framework is not full-fledged discourse analysis per se, the qualitative study is concerned with reflecting the contextualised debates around the mechanisms that 
impede equality in education. Hence, this research recognises that the institutional processes are entrenched in a discursive frame that manifests the perceptions of educational arrangements (Tikly \& Barrett, 2011). In this respect, the research has had two phases: The first phase was the collection of various types of data on the educational arrangements in different country contexts, which provided a comparative illustration of institutional framework; the second stage was the document analysis and the qualitative interviews with the relevant parties in the area of education, which provided a comparative analysis of the debates around the educational arrangements that operated as mechanisms of inequalities.

The research that is carried out as part of a larger research project on justice in Europe looked into the minorities and vulnerable groups' access to education in six countries: Austria, Hungary, the Netherlands, Portugal, Turkey, and the UK. Respectively, the country case selection is bound with the research partners' country of residence. The comparative value of the research pertains to its demonstration of the consequences of divergent and common educational arrangements in the reinforcement of persistent inequalities rather than systematic comparisons of minority positions. Depending on the country contexts, different minorities and vulnerable groups' disadvantaged position in the education system (Muslim minority in the UK, ethnic minority in Austria and Netherlands, Roma in Hungary, Portugal, and Turkey, Afro-descendants in Portugal, Alevi in Turkey) are determined. It should be noted that the definition of minority and minority statutes vary across countries.

The qualitative analysis of the debates around the exclusion of minorities and vulnerable groups in different settings of education analytically dealt with mechanisms with common or different features in each setting. The research strikingly demonstrates that such diverse mechanisms yield similar consequences of educational inequalities that affect the most vulnerable. Also, the selection of a variety of minorities in countries provided the researchers to understand how the categorisation of differences that is historically constructed in different country contexts operates as a mechanism towards the reproduction of categorical inequalities through the education systems.

In each country context, firstly a descriptive analysis was applied looking into commonalities and differences in legal frameworks of education rights, the compulsory school years, the school differentiation systems, the administration of education and the residencybased registration. Based on this comparative outlook of the institutional framework in the studied countries, the research explored the debates around exclusionary mechanisms of the education processes through the qualitative analysis of relevant documents and qualitative interviews with the significant social actors in the area of education. The documents that were analysed vary across the countries, yet they included policy documents, strategy papers by the Ministries, NGO reports, other governmental reports, recommendation papers, and other relevant documents are analysed. Although the document selection varied and depended on the researcher, the documents were selected according to the guidelines of the research that prioritised the minorities' access to education; therefore, themes of exclusion emerged from the fieldwork rather than a dictated framework with established indicators that partner researchers work with. In representing the debates critically, 4-6 in-depth interviews were conducted in each country context, which includes representatives of NGOs (minorities, vulnerable groups, rights and anti-racism), government officials, civil servants, teachers unions, rights protection lawyers, education researchers, and parent associations.

This article draws on the secondary analysis of each country case analysis with a particular focus on the different and common features of the inequalityreproducing mechanisms of the education arrangements in six country contexts with different histories of institutional framework and majority-minority relations.

\section{Institutional Characteristics of the Education Arrangements}

The six countries under study represent diverse institutional frameworks of education including length of compulsory education, legal framework, registration (residence-based) systems, different actors in the education and school differentiation systems. The years of compulsory education range from 9 to 13 years in the countries studied (see Table 1).

The International Covenant of Economic, Social and Cultural Rights (ICESCR) concedes education as a fundamental right. Article 13(1) of the ICESCR emphasises the role of education in the development of human personality, a sense of dignity and effective participation in a free society (ICESCR, 1999). More importantly, ICESCR grants education as an "empowerment right," where "education is the primary vehicle by which economically and socially marginalised adults and children can lift themselves out of poverty and obtain the means to participate fully in their communities" (ICESCR, 1999). Such a framework addresses the role of education in the capability-building of disadvantaged groups. According to the ICESCR, the states are compelled to provide free education (compulsory) to all children, unhindered by their family background (Salat, 2019).

The international human rights instruments, along with the EU equality law, have a significant influence on national constitutional contexts (Salat, 2019). Equal access to education is protected by national laws and, in many countries, it is granted as a constitutional right. In Austria, the objectives of the education system are laid by the Federal Constitutional Law and School Organization Act (Tiefenbacher \& Vivona, 2018). The Fundamental Law of Hungary (Article 11) secures equal access to education and holds the state 
Table 1. Years of compulsory education.

\begin{tabular}{lcr}
\hline Country & Years & Ages \\
\hline Austria & 9 & $6-15$ \\
Hungary & 13 & $3-16$ \\
Netherlands & 13 & $5-18$ \\
Portugal & 12 & $6-18$ \\
Turkey & 12 & $6-18$ \\
UK & 11 & $5-16$ \\
\hline
\end{tabular}

responsible for public education. The right not to be discriminated against in the Fundamental Law also concerns education (Kende, 2018). In the Netherlands, education freedom has a central place in the national law as it is granted as a fundamental right whereas access to education as a right to education is framed by international law. Freedom to education refers to parental choice in selecting the education institution according to their cultural beliefs and values (Hiah, 2018). In Portugal, access to education is arranged by a series of independent articles in the Constitution. Articles 43 and 74 refer to the "freedom to learn and to teach" and "right to education" respectively (Roldao et al., 2018). Free and non-discriminatory education is a constitutional right in Turkey. Article 42 of the Constitution guarantees the right "not to be deprived of education" and free compulsory education for all citizens (Akkan \& Ruben, 2018). The state is held responsible for supporting access to education for individuals who are economically deprived (Akkan \& Ruben, 2018). The UK regulates education by laws enacted by the Parliament Education Acts of 1996 and 2002 and the School Standards Act (1998, as cited in Dupont, 2018). Without an explicit constitutional guarantee, the European Convention of Human Rights' right to education is incorporated into domestic law (Dupont, 2018).

Although the international and national legal frameworks grant education as a fundamental right and urge the states to take necessary measures to secure equal access to education, the diverse education arrangements in different country contexts define the terms of access to education. Such arrangements include centralised and decentralised systems, public and private ownership, school differentiation systems and residency-based registration mechanisms. Hence, all arrangements operate in a rather complex education system that diverges in each context. They are also prone to change depending on the changing political contexts of the countries. Therefore, the complex organisational outlook of education is important to explore as it paves the way for multiple exclusionary mechanisms.

The increasing private ownership of schools emerges as a mechanism that seems to define the boundaries of access to quality education, yet, in many contexts, the presence of private schools is not dominant. In the Netherlands, private schools are not numerous and do not have a high standing (Hiah, 2018). In Austria, the majority of the students are also enrolled in federal state-run public schools (90\%). Private schools, which constitute $8 \%$ of the schools, are mostly denominational (Tiefenbacher \& Vivona, 2018). The public and private separation in schooling is a complex one as in many countries the private schools are funded by the state. In Portugal, although the majority of the schools are publicly run, the private and independent schools have a place in the system. There are also schools run under the public-private partnership model, in which the state makes payments to the private schools. In this model, these schools, although private, cannot request tuition fees from the students (Roldao et al., 2018). In Austria, the majority of private schools are also funded by the state, yet they charge tuition fees (Tiefenbacher \& Vivona, 2018). In Hungary, private schools also receive public funds and they charge fees like in Austria (Kende, 2018).

The separation of public and private schools in a complex set of organisational relations could also operate to the extent that the education system is centralised or decentralised. The UK is a strong example of a highly decentralised school system. The state-funded and all-through schools which are community and foundation schools are run by a local authority, under the shared governance of local authorities and other parties which are mostly religious organisations (Dupont, 2018). There are also "academies" and "free schools" governed by private foundations (under a funding agreement with the state) and "independent schools" that rely on tuitions without receiving any state funds (Dupont, 2018). In Hungary, there is a trend towards centralisation under the current government, which is a drastic shift from the decentralised education system of the 90s. This has manifested itself in the transformation of the schools run under the Municipalities, which are now being governed by the central state, unless the Municipality area has a population above 3000 (Kende, 2018). Turkey is a salient case of a highly centralised education system. The public schools operate under the Ministry of Education. There are also private schools run under the mandate of the Ministry, however, these schools charge high tuition fees (Akkan \& Ruben, 2018).

The school systems also vary concerning the centrality or diversity of curriculum followed at schools. In the UK, the schools governed by local authorities follow the national curriculum whereas academies, free schools 
and independent schools are not required to follow the national curriculum. The only requirement for them is to include linguistic, mathematics, physical, and aesthetic skill development in their curriculum (Dupont, 2018). In the Netherlands, all schools follow the national curriculum, yet the denominational schools have the freedom to provide religious education and they are also autonomous in their procedures of teacher recruitment and student admission. Whereas public schools that have a secular and "neutral" character, they do not have the liberty to provide a particular religious education or to select teachers regarding their belief system, and they are open to all students regardless of their beliefs (Hiah, 2018).

In both the centralised and decentralised education systems, the arrangements are towards maintaining equal access and accommodating diversity. In the Netherlands, the "institutionalised" dual school system constitutes "neutral" public schools and denominational schools (Hiah, 2018). "Neutral" education rests on the principle of religious diversity, equality, and non-discrimination. The denominational schools are commonly Protestant, Catholic, and Jewish schools but recently Muslim and Hindustani schools have also been incorporated (Hiah, 2018). They are all funded by the State. The denominational schools (Roman-Catholic, Protestant Christian) identified as high-quality education institutions are also favoured by parents that belong to other belief systems or are secular. In Hungary, under an agreement with the state, schools can be opened by churches and religious denominations. The church schools that are taking over the secular schools are a recent phenomenon (Kende, 2018).

In certain countries, residency-based registration defines the access process. In Austria, registration in public schools is residency-based according to a system of administrative districts, although this has been made flexible. In Hungary, public school registration is also residency-based, yet families are free to choose a school outside of their district. In Turkey, registration to public primary schools has been done by a computerised system that places the students in schools nearest to their residence addresses.

As it is maintained, in all countries under study, although equal access to education is granted by the national laws under the international human rights framework, it is often the arrangements around the diverse school types that identify the terms of access to education in each context. In the following section, we explore how educational arrangements operate as mechanisms that hinder the role of education as an equalitycreating entity.

\section{A Comparative Perspective on the Perceived Mechanisms that Impede Access to Education}

School segregation is one of the mechanisms that operate as a source of injustice and inequality for students with minority backgrounds. In all countries under study, school segregation is deliberated as a mechanism that generates exclusionary practices in education. Yet, the features of school segregation may change depending on the education system, including differentiation of schools as well as residency requirements for enrolment. However, as the study focuses on mechanisms around minorities' access to education, the different minority positions in different contexts also define the features of these mechanisms. In certain contexts, like Hungary, the debate is around the drastically segregated character of the system which has paved the way to a duality between schools, referred to as "homogeneity within the schools and heterogeneity between schools," which is associated both with the socio-economic background of parents as well as residential segregation, which is mostly a Roma condition (Kende, 2018, p. 20). The differences in quality of schools that overlap with the socio-economic status of the families act as a stratification mechanism that particularly affects minorities' exclusionary position in the education system.

Hence, the economic and cultural aspects of the exclusionary dynamics do not manifest themselves in the same way for all minority groups. The country cases in our study strongly demonstrate the persistently disadvantaged position of Roma children in education. Particularly in Hungary, Turkey, and Portugal, the discourses on Roma's access to education illustrate how segregation operates as a mechanism of not just exclusion but how it reproduces persistent inequalities within the education system by creating disadvantaged schools for already disadvantaged groups. In Hungary, the debates illustrate that Roma have access to disadvantaged primary schools without resources; the education itself is a stratifying mechanism as it does not provide the necessary skills for Roma. Low-quality vocational schools are what are available for Roma, where the drop-out rates are also high (Kende, 2018). In Turkey, the inability of the school system to provide Roma with the inclusionary space to develop capabilities that influence their life chances has been a major debate as school withdrawal is high among the Roma students who start working to contribute to family income (Akkan \& Ruben, 2018). In many contexts, school segregation intertwines with track systems and operates as a mechanism of reproducing categorical inequalities as the debates in Portugal also reveal that Roma, as well as Afro-descendants, are pushed into vocational schools that do not provide a path towards higher education (Roldao et al., 2018). In a parallel vein, in the Netherlands, it has also been exposed that socioeconomic status, tangled with minority and migration background, has a high correlation with the quality of the school that is being accessed (Hiah, 2018).

These cases demonstrate that school segregation is a strongly entrenched mechanism that reproduces multiple inequalities of socio-economic status and minority background when the school quality is associated with the categorically disadvantaged position of the 
enrolled students. The debates in the Netherlands also reveal another story; that there are high achieving schools with low socio-economic and minority background students (Hiah, 2018). Such a contrasting story draws attention to the role of education policies for more egalitarian education arrangements. The inclusionary space that the school creates for the capability development is associated with the inclusionary education arrangements including the allocation of resources. In the Austrian case, discourses contemplate the scarcity of resources in providing inclusionary school arrangements with high-quality teaching to meet the needs and enhance the capability of students with different backgrounds (Tiefenbacher \& Vivona, 2018). Marketisation trends also exacerbate this situation. In the UK, as it has been revealed, the transfer of school governance from local authorities to private foundations that was initiated by the Labour party and bolted by the Coalition government in 2010 was a significant move towards marketisation (Dupont, 2018).

School segregation mostly coincides with spatial, namely residential segregation. In Austria, the discourses reveal salient school segregation associated with the quality of the school. The schools referred to as "left-over schools" (Restschulen) or "hot spot schools" (Brennpunktschulen) reflect the spatial character of school segregation as the socio-economic development of the neighbourhood where the school is situated determines the main difference between the "hot spots" and "left-overs" (Tiefenbacher \& Vivona, 2018). The neighbourhoods with residents from minority background with low socio-economic status host the public and vocational schools, stigmatised as the "left-over schools" (Restschulen), where children with a disadvantaged background go (Tiefenbacher \& Vivona, 2018). Such segregation is being reinforced by a residencybased registration scheme in Austria where the quality of the school, the disadvantaged position of the individuals and spatial underdevelopment come together and create the phenomenon of "left-over schools." The debates in Austria also draw attention to the aspect of language proficiency: The migration background of the students emerge as a major disadvantage in the school system, as the left-over schools, mostly attended by students with a minority background, are marked by problems of low proficiency of German language (Tiefenbacher \& Vivona, 2018). The debates reveal that a large number of children who do not speak German as a first language often pose large challenges and contribute to schools' attributed status as Restschulen, particularly in Vienna (Tiefenbacher \& Vivona, 2018). As the case of Austria strongly demonstrates, segregation in education is always in tandem with the categorical inequalities concerning ethnicity, religion, socio-economic background, as well as "cultural" and language differences. The differences in the minority position in different contexts demonstrate that the persistent inequalities that the minorities experience reveal the highly segregated envi- ronment that is being reflected in contextualised debates in different country settings.

Although school choice is not a matter of discrimination in itself, it might also become a determinant of school segregation with implications for exclusionary processes concerning the economic or cultural background of children. The schools' differentiation systems influence this process. Among the countries studied, the denominational schools in the Netherlands and the church schools in Hungary, which have the public support of middle-class families, are being debated within the framework of school choice and segregation. These schools with high-quality education influence the process of segregation through mechanisms like school choice. The debates reveal that the school choice of middle-class families in Hungary reinforces the relationship between the quality of the school and the socioeconomic background of students. As the debates lay bare, this situation particularly pertains to the propensity of non-Roma families to choose schools which Roma students do not attend (Kende, 2018). The phenomenon of the "white flag" is salient in the debates on school choice in Hungary, which is a strong determinant of school segregation as the literature also points out. The debates in Hungary also manifest how categorical inequalities are being internalised by vulnerable groups. The school choice of Roma in Hungary supports the homogenisation within the school and the disadvantaged schools based in Roma neighbourhoods are preferred by Roma parents as in mixed schools the discrimination is more salient. Besides, the high expectation of high-quality schools is creating new forms of vulnerabilities for Roma parents (Kende, 2018). In a larger normative framework, although the parents have the freedom to choose the school, the process operates as a form of capability deprivation (unfreedom) for children with disadvantaged backgrounds, which reinforces the persistent inequalities.

The residency-based measures operate as mechanisms to provide equal access to education. Yet, they are perceived as a major constraint for school choice. The residency-based measures are hard to enforce on middle-class families than on the more disadvantaged groups, like Roma. In Portugal, residency-based registration is defended to deter ethnic and racial segregation. Yet, middle-class families find ways to attain school choice by forging their address or sending their children to private schools, which again provides a sort of homogeneity concerning ethnicity and socioeconomic status (Roldao et al., 2018). Also, the claims of middle-class families for quality education reproduce the "white flag" phenomenon in the educational context, like in Portugal. From a different perspective, in Turkey, residency-based registration operates as a mechanism that restrains the freedom of school choice of the parents to choose schools which they find to be of good quality and which provide an education that is in conformity with their values (Akkan \& Ruben, 2018). The phenomenon of 
"religionalisation" with the expansion of Imam Hatip schools (religion-based schools) manifests new spatial inequalities in the education system. The vast opening of Imam Hatip schools and the conversion of secular schools to Imam Hatip schools threaten the freedom of school choice. While the discourses of the state in advocating for the Imam Hatip schools are an expansion of freedom of choice for the religious majority, this leads to injustices among groups like Alevi, but also the secular middle-class who do not favour religious schools for their children. The enforcement of religious schools through the residency-based system pushes the families to move out of the neighbourhoods or send their children to private schools (Akkan \& Ruben, 2018).

The debates in Austria also reveal that since flexibility was brought to residency-based registration in 2017, the educated parents with high socio-economic status have been able to have access to good quality schools outside of their neighbourhood zones. Such an informed choice that goes beyond the spatial boundaries is a class matter (Tiefenbacher \& Vivona, 2018).

Freedom of education is a prevalent discourse in the context of the Netherlands that is being manifested in the school differentiation system. In such a system, the school choices of the "white" middle class that holds the majority operate as a mechanism of exclusion. In the Netherlands, where ethnicity and race are determinants of socioeconomic status, the debates draw attention to ethnicity-based school segregation and uneven ethnic distribution of pupils across schools between the white majority and the ethnic minority (Hiah, 2018). The denominational schools can deny students who do not comply with the community value that they represent, even though is not being operationalised in practice. Yet, the overrepresentation of minority groups in public schools reveals veiled segregation in place (Hiah, 2018). Revealed by the debates, the emphasis is on socioeconomic disadvantage rather than ethnicity, which implies the veiled influence of freedom of education and its institutionalisation of segregation in the school differentiation system that pertains to the stratification in the majority-minority relations and persistent inequalities among the ethnic minorities. The language of freedom around family values is also salient in Hungary. After 2010, to target Roma students, a series of exemptions were introduced by the Conservative-Christian government which supports the "religious and philosophical freedom" and the "right of recognised nationalities to operate their schools" (Kende, 2018, p. 30). Hence, the exemptions support a segregated education system that perpetuates the categorisation of differences and persistent inequalities in the context of Hungary.

The freedom of school choice, when accompanied by the cultural preferences and claims for community values, becomes a more complex mechanism of segregation that is being debated heavily in all contexts. The freedom of choice is being contemplated concerning the role of education in building the social cohesion of society, which is very much reflected in the context of the UK. The proliferation of faith-based schools is being discussed concerning the "balkanisation" of society, where cultural segregation emerges as a school choice among different ethnic and religious communities (Dupont, 2018). The freedom to choose the school that reflects the values of the parents could operate as a mechanism of cultural and ethnic segregation that sets the boundaries of majority and minority relations. Hence, in the UK, debates reveal a tension between making school culture responsive to family aspirations, which calls for the maximisation of parental choice and decentralised governance, and the prevention of disparities in knowledge acquisition, which calls for greater state oversight (Dupont, 2018). The discourses on the tensions that might appear between freedom of choice and the objectives of education defined in terms of equal access and social cohesion differ in their framing.

The debates on the different features of freedom for school choice and their reflection in school segregation manifest how mechanisms of educational arrangements aiming at parental freedom in decision-making could reinforce and reproduce categorical inequalities. The debates across different countries expose the tension between the freedom of education that benefits middle-class families as a "white flag" phenomenon and efforts in maintaining equal access to education. The debates also manifest how the value-driven choices and claims for education make the politics of equality in education an even more complex issue.

\section{Conclusion}

In our pluralistic societies, education is a contested area where the boundaries of inclusion and exclusion are drawn through different mechanisms. The debates in the country cases examined in the article vividly illustrate how the mechanisms of school segregation intertwined with spatial segregation, residency-based registration, school differentiation and school choice could reproduce "categorical inequalities" in a given context. As it is being deliberated, educational arrangements through different mechanisms categorise differences not just in accordance with the socio-economic status of the family but with more salient categories like ethnicity, race, and religion. In this respect, the role of education as a capability-building institution, particularly for children from minorities and vulnerable groups, becomes more contested. Although there is a consensus that education is a fundamental right that is being secured by constitutional laws as well as by the incorporation of international law in the domestic legal system, the country cases demonstrate diverse educational arrangements which identify the unequal terms of access to quality education in each context.

Dealing with different contexts that have their path dependencies in the arrangements of education and the historical construction of minorities provides significant 
insights in understanding how different features of segregation in education operate as mechanisms of inequality for the disadvantaged students concerning their socioeconomic status, ethnicity, race, and minority background. The spatial dimension of school segregation is evident in all cases, which is also intertwined with the ethnicity and socioeconomic status in different country contexts, as the case of Roma constitutes a particularly salient example. Residency-based registration rules can be strict or lenient, but it is mostly the middle-class parents, with the necessary economic and cultural resources and capital, who try and can find ways of putting their children in good schools, as is observed in many country cases. This defines a pattern where the "white flight" of the advantaged and the lack of resources (economic and cultural), as well as the "adaptive expectations," of the disadvantaged lead to the emergence of low-quality schools with their segregated nature. Political attempts to emphasise the good performance of the education system rather than address the exclusionary dynamics fostered by school segregation contribute to the persistent inequalities concerning the arrangements of education. This is also reinforced by the prevailing market-oriented trends which have not been the main focus of this article, yet hold importance for debates concerning equality.

Unless the "categorical inequalities" entrenched in the majority-minority relations in diverse contexts are not adequately addressed by the politics of education, they will continue to define the boundaries of educational arrangements in the capability development of children with disadvantaged backgrounds. Yet, it remains difficult to reach a conclusion concerning how equal access can be improved by policy intervention, especially since the categorical inequalities, in their spatial dimension, continue to be important regardless of the rules that regulate the registration and school admissions in different country contexts. Education reforms for a more inclusive education system could be welcomed by most associations who represent minorities and vulnerable groups as well as parents in all country contexts. However, the reform process would only be successful to the extent that it adequately addresses the controversies around the type of education that could positively respond to diverse claims of education and develop the capabilities of children unconstrained of their advantaged or disadvantaged background.

\section{Acknowledgments}

We would like to thank the editors of this thematic issue and the reviewers for their thorough review and insightful suggestions. This project has received funding from the European Union's Horizon 2020 research and innovation programme under grant agreement No. 727112.

\section{Conflict of Interests}

The authors declare no conflict of interests.

\section{References}

Akkan, B., \& Ruben, D. (2018). Discourses on minorities (and vulnerable groups) access to education: Country case Turkey. Unpublished country report for ETHOS D 4.3.

Alegre, M. A., \& Ferrer, G. (2010). School regimes and education equity. Some insights based on PISA 2006. British Educational Research Journal, 36(3), 433-462.

Alexiadou, N. (2019). Framing education policies and transitions of Roma students in Europe. Comparative Education, 55(3), 422-442.

Allen, D., \& Reich, R. (Eds.). (2013). Education, justice, and democracy. University of Chicago Press.

Andersson, E., Östh, J., \& Malmberg, B. (2010). Ethnic segregation and performance inequality in the Swedish school system: A regional perspective. Environment and Planning, 42(11), 2674-2686.

Arabadjieva, K. (2016). Challenging the school segregation of Roma children in Central and Eastern Europe. The International Journal of Human Rights, 20(1), 33-54.

Benito, R., Alegre, M. A., \& Gonzàlez, I. (2014). School segregation and its effects on educational equality and efficiency in 16 OECD comprehensive school systems. Comparative Education Review, 58(1), 104-134.

Bonal, X., \& Bellei, C. (2018). The renaissance of school segregation in a context of globalization. In B. Xavier \& C. Bellei (Eds.), Understanding school segregation: Patterns, causes and consequences of spatial inequalities in education (pp. 1-35). Bloomsbury.

Bunar, N., \& Ambrose, A. (2016). Schools, choice and reputation: Local school markets and the distribution of symbolic capital in segregated cities. Research in Comparative and International Education, 11(1), 34-51.

Butler, T., \& Hamnett, C. (2007). The geography of education: Introduction. Urban Studies, 44, 1161-1174.

Cashman, L. (2017). New label no progress: Institutional racism and the persistent segregation of Romani students in the Czech Republic. Race Ethnicity and Education, 20(5), 595-608.

International Covenant of Economic, Social and Cultural Rights. (1999). General comment no. 13: The right to education (E/C.12/1999/10).

Collins, P. H. (1998). It is all in the family: Intersections of gender, race and nation. Hypatia, 13(3), 62-82.

Council of Europe. (2017). Fighting school segregation in Europe through inclusive education. https://rm. coe.int/fighting-school-segregationin-europethroughinclusive-education-a-posi/168073fb65

Denessen, E., Driessena, G., \& Sleegers, P. (2005). Segregation by choice? A study of group specific reasons for school choice. Journal of Education Policy, 20(3), 347-368.

Dupont, P.-L. (2018). Political discourses on educational justice and Muslims in the UK. Unpublished country report for ETHOS D 4.3. 
Domina, T., Pemmer, A., \& Penner, E. (2017). Categorical inequality: Schools as sorting machines. Annual Review of Sociology, 43(1), 311-330.

Dupriez, V., Dumay, X., \& Vause, A. (2008). How do school systems manage pupils' heterogeneity? Comparative Education Review, 52(2), 245-273.

Hiah, J. (2018). National discourses about minority social rights with respect to access to education. Unpublished country report for ETHOS D 4.3.

Keddie, A. (2012). Schooling and social justice through the lenses of Nancy Fraser. Critical Studies in Education, 53(3), 263-279.

Kende, A. (2018). Discourses on Roma students' access to education: Inclusionary and exclusionary aspects. Unpublished country report for ETHOS D 4.3.

Knijn, T., \& Akkan, B. (2020). Mechanisms that impede justice. In T. Knijn \& D. Lepianka (Eds.), Justice and vulnerability in Europe: An interdisciplinary approach (pp. 214-232). Edward Elgar Publishing.

Levin, B. (1998). An epidemic of education policy: (What) can we learn from each other? Comparative Education, 34(2), 131-141.

Lynch, K., \& Baker, J. (2005). Equality in education: An equality of condition perspective. School Field, 3(2), 131-164.

OECD. (2013). PISA 2012 results: Excellence through equity-Giving every student the chance to succeed (Vol. 2). OECD Publishing.

OECD. (2018). Equity in education: Breaking down barriers to social mobility, PISA. OECD Publishing.

Power, S. (2012). From redistribution to recognition to representation: Social injustice and the changing politics of education. Globalization, Societies and Education, 10(4), 473-492.

Power, S., \& Frandji, D. (2010). Education markets, the new politics of recognition and the increasing fatalism towards inequality. Journal of Education Policy, 25(3), 385-396.

Roldao, C., Bruno, S. M., \& Meneses, M. P. (2018). Political and advocacy discourse analysis of inclusionary and exclusionary aspects of education. Unpublished country report for ETHOS D 4.3.

Salat, O. (2019). Comparative report on the right to education: An assessment of the legal framework of six countries from the perspective of recognitive and redistributive justice (ETHOS Report D 3.6.). ETHOS. https://ethos-europe.eu/sites/default/files//docs/ d3.6_website_report_completed.pdf

Saporito, S. (2003). Private choices, public consequences: Magnet school choice and segregation by race and poverty. Social Problems, 50(2), 181-203.

Sen, A. (1999). Development as freedom. Alfred A. Knopf. Sen, A. (2000). Social exclusion: Concept application and scrutiny (Social Development Papers No. 1). Asian Development Bank. https://www.adb.org/sites/ default/files/publication/29778/social-exclusion.pdf

Shores, K., Kim, H. E., \& Still, M. (2020). Categorical inequality in Black and White: Linking disproportionality across multiple educational outcomes. American Educational Research Journal, 57(5), 2089-2131.

Sime, D., Fassetta, G., \& McClung, M. (2018). It's good enough that our children are accepted: Roma mothers' views of children's education post migration. British Journal of Sociology of Education, 39(3), 316-332.

Steiner-Khamsi, G. (2003). Cultural recognition or social redistribution: Predicaments of minority education. In Y. Iram (Ed.), Education of minorities and peace education in pluralistic societies (pp. 15-28). Greenwood Press.

Tiefenbacher, W., \& Vivona, M. (2018). Minorities and access to education in Austria. Unpublished country report for ETHOS D 4.3.

Tilly, C. (1999). Durable inequality. University California Press.

Tikly, L., \& Barrett, A. M. (2011). Social justice, capabilities and the quality of education in low income countries. International Journal of Education Development, 31, 3-14.

Unterhalter, E. (2003). The capabilities approach and gendered education. Theory and Research in Education, 1(1), 7-22.

Unterhalter, E. (2012). Poverty, education, gender and the millennium development goals: Reflections on boundaries and intersectionality. Theory and Research in Education, 10(3), 253-274.

Walker, M. (2006). Towards a capability-based theory of social justice for education policy-making. Journal of Education Policy, 21(2), 163-185.

Winker, G., \& Degele, N. (2011). Intersectionality as multilevel analysis: Dealing with social inequality. European Journal of Women's Studies, 18(1), 51-66.

\section{About the Authors}

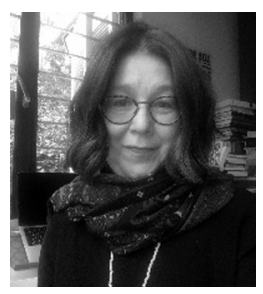

Başak Akkan (PhD) is a Senior Research Fellow at the Social Policy Research Centre (Social Policy Forum) and a Lecturer at the Graduate Program in Social Policy, both at Boğaziçi University. She has published in journals such as Social Politics, Journal of Gender Studies, Feminist Theory, Child Indicators Research, and Children and Youth Services Review. Her research interests are in the theories of the welfare state, justice, and intersectionality focusing on care policies, child well-being, education, and life course perspective on social policies. 


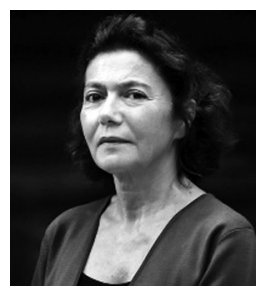

Ayşe Buğra is Professor Emerita at Boğaziçi University and an affiliate of the Boğaziçi University research centre Social Policy Forum, which she co-founded in 2004. She has published in academic journals such as the International Journal of Middle East Studies, Economics and Philosophy, International Journal of Urban and Regional Research, Social Politics, and Development and Change. Her books written and edited in English include New Capitalism in Turkey: The Relationship between Politics, Religion and Business (Edward Elgar, 2014), Trajectories of Female Employment in the Mediterranean (Palgrave MacMillan, 2012) and Reading Karl Polanyi for the 21st Century (Palgrave MacMillan, 2007). 